\title{
STUDI PEMBUATAN PERMEN DARI AIR KELAPA TERHADAP KARAKTERISTIK DAN PENERIMAAN KONSUMEN
}

\author{
M. Jurait, S.TP(1) dan Hermiza Mardesci, S.TP., MP ${ }^{(2)}$ \\ ${ }^{(1)}$ Alumni Teknologi Pangan Faperta UNISI \\ ${ }^{(2)}$ Dosen Teknologi Pangan Faperta UNISI \\ mimzaaci@yahoo.co.id
}

\begin{abstract}
Abstrak
Penelitian ini bertujuan untuk mengetahui studi pembuatan permen dari air kelapa terhadap karakteristik dan penerimaan konsumen. Penelitian ini dilaksankan dilaboraturium Teknologi Pangan Fakultas Pertanian Universitas Islam Indragiri. Metode penelitian adalah dengan menggunakan Rancangan Acak Lengkap (RAL) dengan 4 perlakuan yaitu $\mathrm{A}=20 \%$ air kelapa/bb : $40 \%$ air $/ \mathrm{bb}, \mathrm{B}=30 \%$ air kelapa/bb : $30 \%$ air/bb, C = $40 \%$ air kelapa/bb : $20 \%$ air/bb dan $\mathrm{D}=50 \%$ air kelapa/bb : $10 \%$ air/bb,dengan tiga kali ulangan.

Analisa dilakukan untuk menentukan kadar air, kadar gula, $\mathrm{pH}$, organoleptik (aroma, rasa, warna dan tekstur). Untuk analisa yang terbaik adalah A (20\% air kelapa/bb : $40 \%$ air/bb) dengan kadar air total 8.1160, dengan hasil uji organoleptik yang disukai panelis, warna $3,8500 \%$ aroma $3.7000 \%$, rasa 3.6500 , dan tekstur 3.4500. pada pembuatan permen air kelapa dengan penambahan air $10 \%, 20 \%, 30$ $\%$, dan $40 \%$. Belum menghasilkan permen kadar air dengan standar SNI.
\end{abstract}

Kata kunci : Permen, air kelapa, karateristik

\section{PENDAHULUAN}

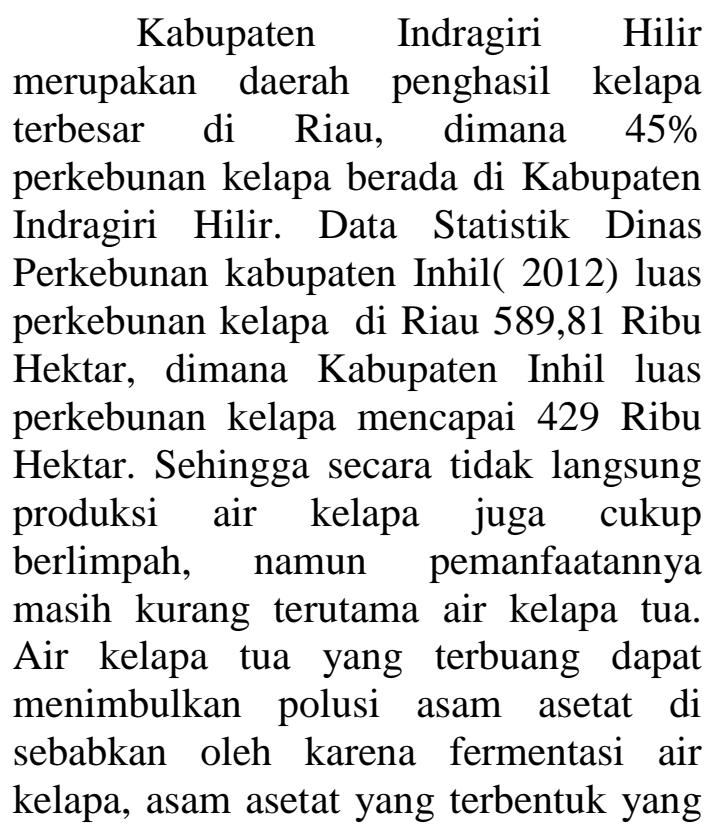

dapat menyebabkan gangguan pada kesuburan lahan pertanian.

Pemanfaatan air kelapa tua di Kabupaten Indragiri Hilir masih terbatas pada pembuatan nata de coco, kecap air kelapa, dan belum di manfaatkan untuk produk lain. Padahal air kelapa bisa di olah produk permen.

Menurut (Buckle, dkk., 2009). Permen adalah sebuah produk yang di buat dengan mendidihkan campuran gula dan air bersama dengan bahan pewarna dan pemberi rasa sampai mencapai kadar air kira-kira 3\%. Biasanya digunakan suhu kurang lebih $90^{\circ} \mathrm{C}-150^{\circ} \mathrm{Csebagai}$ penunjuk kandungan padatan dan didihkan hingga kandungan padatan yang diinginkan. Untuk membuat 
permen dengan daya tahan yang memuaskan terletak pada pembuatan produk dengan kadar air minimum dengan sedikit saja kecenderungan untuk mengkristal.Gula ditambahkan ke dalam bahan pangan dalam konsentrasi yang tinggi atau (paling sedikit 40\% padatan terlarut) sebagian dari air yang ada tidak tersediauntuk pertumbuhan mikroorganisme dan aktivitas air dari bahan pangan berkurang (Buckle,dkk. 1987). Kristalisasi dalam produk seperti ini disebut graining dan mengakibatkan penampilan yang kurang memuaskan dan terasa kasar pada lidah jika dikonsumsi.

Air kelapa di Kabupaten Indragiri Hilir belum dimamfaatkan secara optimal. Air kelapa dapat di buat menjadi permen bahan utama dalam pembuatan permen adalah air kelapa,air dan gula, yang menjadi masalah belum di ketahui komposisi yang tepat untuk komposisi air kelapa yang dapat di dalam pembuatan permen air kelapa ini. Berdasarkan hal tersebut maka penulis ingin melakukan penelitian dengan judul Studi pembuatan permen dari air kelapa terhadap karakteristik dan dapat di terimah oleh konsumen.

\section{Tujuan Penelitian}

Penelitian ini bertujuan untuk mengetahui studi pembuatan permen dari air kelapa terhadap karakteristik dan penerimaan konsumen.

\section{Manfaat Penelitian}

Manfaat penelitian ini adalah :

1. Menjadi salah satu sumber pengetahuan tentang studi pembuatan permen dari air kelapa agar dapat di kembangkan.

2. Menambah pengetahuan kepada mahasiswa dan masyarakat tentang pemanfaatan air kelapa tua yang dapat diolah menjadi permen sehingga dapat menambah daya guna dan nilai ekonomi dari air kelapa.

\section{Bahan}

Bahan yang digunakan adalah air kelapa tua, gula sukrosa, air putih. Adapunbahan yang digunakanuntukanalisiskimia yaitu: Aquades, pbasetat, $\mathrm{Na}$ Oksalat, $\mathrm{Na}$ hidrat, larutanluffschool $\mathrm{KI}, \mathrm{H}_{2} \mathrm{SO}_{4}$,dan $\mathrm{Na}$ Thiosulfat. Uji total mikroba: Plat Count Agar (PCA), danNaCl.

\section{Alat}

Alat yang digunakan untuk pengolahan dalam penelitian ini adalah, panci, wajan,kompor, pisau, kain saring, dan adapun alat yang digunakan untuk analisis kimia yaitu pengujian gula reduksi : Timbangan, labu takar, Erlenmeyer, dan incubator. Uji kadar air: Cawan porselen, oven, desokator, penimbang, dan cawan porselen.

\section{Metode penelitian}

Rancangan percobaan
dilakukan dengan menggun
Rancangan Acak Lengkap (RA
dengan perlakuan perbandingan
kelapa dengan air dengan persen
gula tetap $40 \%$, adapun perlaku
sbb:
$\mathrm{A}=20 \%$ air kelapa/bb : $40 \%$ air $/ \mathrm{bb}$
$\mathrm{B}=30 \%$ air kelapa/bb : $30 \%$ air $/ \mathrm{bb}$
$\mathrm{C}=40 \%$ air kelapa/bb : $20 \%$ air $/ \mathrm{bb}$
$\mathrm{D}=50 \%$ air kelapa/bb : $10 \%$ air/bb

\section{Proses Pembuatan Permen Air kelapa}

Diagram alir proses pembuatan permen air kelapa dapat dilihat pada bagian di bawah ini :

1. Persiapanbahan

Mempersiapkan bahan-bahan yang akan digunakan seperti: air kelapa tua, gula pasir, air putih, Natrium 
benzoat di siapkan sesuai dengan perlakuan.

2. Sortasi

Bertujuan untuk memilih mutu bahan yang baik dan layak untuk dijadikan bahan olahan permen. Didalam pengolahan permen air kelapa di pilih air kelapa dari kelapa yang sudah tua, dari air kelapa yang di gunakan air kelapa yang masi segar yang waktu pemotongan paling lama 8 jam.

3. Penyaringan

Air kelapa di saring dengan kain penyaring yang bertujuan untuk memisahkan benda-benda yang terdapat dalam air kelapa.

4. Pencampuran

Semua bahan di campur sesuai dengan perlakuan seperti air kelapa, gula sukrosa dan air putih.

5. Pemasakan

Gula sukrosa di masak bersama air dan air kelapa sampai berbentuk kental dengan suhu yang di gunakan $\pm 90^{\circ} \mathrm{C}-100^{\circ} \mathrm{C}$ selama \pm 45 menit. Kemudian larutan didiamkan selama \pm 10 menit lalu di lakukan pengolahan lanjut hingga berbentuk permen.
6. Pemotongan

Permen air kelapa dipotong dengan ukuran lebih kurang $1 \mathrm{~cm} \mathrm{x} 1 \mathrm{~cm} \mathrm{x}$ $1 \mathrm{~cm}$. Sesudah pemotongan lalu permen didiamkan sampai mengering tidak lengket, dan di simpan suhu ruang $27^{\circ} \mathrm{C}-32^{\circ} \mathrm{C}$.

7. Pengemasan

Selanjutnya permen tersebut dikemas setelah permen kering dengan bahan pengemasan yang tidak membahayakan kesehatan, seperti gelas, atau plastik, agar tetap higienis.

\section{HASIL DAN PEMBAHASAN}

\section{Kadar Air}

Air merupakan komponen penting dalam bahan pangan yang dapat mempengaruhi penampakan, tekstur, dan cita rasa makanan. Kadar air dalam bahan makanan ikut menentukan kesegaran dan daya awet bahan makanan tersebut (Winarno. 1991).

Hasil analisis sidik ragam menunjukan bahwa jika $\mathrm{F}$ hitung lebih besar dengan $\mathrm{F}$ tabel $(21.00>4.07)$ maka dilakukan uji lanjut Tukey dengn taraf 5 $\%$, hal ini berarti bahwa perbandingan air kelapa dan air memberikan pengaruh yang berbeda nyata terhadap kadar air.

Tabel 3. Rata-rata Kadar Air Permen Air Kelapa berdasarkan perbandingan air kelapa dan air.

\begin{tabular}{|c|c|}
\hline Perlakuan & Kadar Air (\%) \\
\hline $\mathrm{A}=(20 \%$ air kelapa/bb $: 40 \%$ air/bb) & $8.1160 \mathrm{a}$ \\
\hline $\mathrm{B}=(30 \%$ air kelapa/bb $: 30 \%$ air/bb) & $9.6564 \mathrm{ab}$ \\
\hline $\mathrm{C}=(40 \%$ air kelapa/bb $: 20 \%$ air/bb) & $10.3623 \mathrm{bc}$ \\
\hline $\mathrm{D}=(50 \%$ air kelapa/bb $: 10 \%$ air/bb) & $11.9096 \mathrm{c}$ \\
\hline
\end{tabular}

Keterangan : Angka-angka yang di ikuti huruf yang sama berarti berbeda nyata menurut uji lanjut Tukey pada taraf nyata 5\%. 
Tabel 3. Memperlihatkan bahwa perlakuan A berbeda tidak nyata dengan perlakuan $\mathrm{B}$, tapi bebeda nyata dengan perlakuan $\mathrm{C}$ dan $\mathrm{D}$, perlakuan $\mathrm{B}$ berbedatidak nyata dengan $\mathrm{C}$, tapi berbeda nyata dengan $A$ dan $D$, perlakuan $\mathrm{C}$ berbeda tidak nyata dengan D, tapi berbeda nyata dengan A. Dari perlakuan tersebut dapat disimpulkan bahwa, semakin besar konsentrasi air kelapa yang ditambahkan dalam pembuatan permen air kelapa, maka kandungan air juga semakin meningkat. Sebaliknya semakin sedikit air kelapa yang digunakan, maka kandungan air juga semakin sedikit. Rendahnya kadar air pada perlakuan A disebabkan karenaair kelapa mengandung sukrosa, hal ini sangat berpengaruh adanya kandungan air jika di kaitkan dengan gula sukrosa seperti yang terdapat perlakuan D (50\% air kelapa/bb : $10 \%$ air/bb). 11.9096. Kadar air permen keras memilki batas maksimum 1-3\% Standar SNI (2008). Dengan jenis konsentrasi air kelapa yang berbeda kadar air permen air kelapa melebihi yang di tetapkanStandar SNI (2008). Di mana faktor yang dapat mempengaruhi permen keras antara lain, penambahan gula, pemilihan buah, pemasakan, (Santoso 2010).

Hal ini berhubungan dengan adanya aktivitas air dari bahan pangan yang juga berkurang karena pengaruh penambahan gula dalam konsentrasi yang tinggi. Sesuai dengan sifat gula sukrosa yang bersifat higroskopis, yaitu kemampuan untuk menyerap dan menahan air (Mc Willioms).

Menurut winarno (2002), semua bahan makanan mengandung airdalam jumlah yang berbeda-beda, baik itu bahan makanan hewani maupun nabati dan kadar air bahan baku akan mempengaruhi kadar air produk hasil olahan.

\section{Kadar Gula}

Penambahan sukrosa pada pembuatan permen memiliki fungsi untuk memberikan rasa manis, dan dapat pula sebagai pengawet, yaitu dalam konsentrasi tinggi menghambat pertumbuhan mikroorganisme dengan cara menurunkan aktivitas air dari bahan pangan (Malik, 2010).

Hasil analisis sidik ragam menunjukan bahwa jika $\mathrm{F}$ hitung lebih besar dengan $\mathrm{F}$ tabel $(18.47>4.07)$ maka dilakukan uji lanjut Tukey dengn taraf $5 \%$, hal ini berarti bahwa perbandingan air kelapa dan air memberikan pengaruh yang berbeda nyata terhadap kadar gula yang di hasilkan, uji lanjut Tukey.

Tabel 4. Rata-rata Kadar Gula Permen Air Kelapa berdasarkan perbandingan air kelapa dan air.

\begin{tabular}{|c|c|}
\hline Perlakuan & Kadar Gula (\%) \\
\hline $\mathrm{A}=(20 \%$ air kelapa/bb $: 40 \%$ air/bb $)$ & $39.0005 \mathrm{a}$ \\
\hline $\mathrm{B}=(30 \%$ air kelapa/bb $: 30 \%$ air/bb $)$ & $40.9333 \mathrm{ab}$ \\
\hline $\mathrm{C}=(40 \%$ air kelapa/bb $: 20 \%$ air/bb $)$ & $42.3533 \mathrm{bc}$ \\
\hline $\mathrm{D}=(50 \%$ air kelapa/bb $: 10 \%$ air/bb $)$ & $44.5914 \mathrm{c}$ \\
\hline
\end{tabular}

Keterangan : Angka-angka yang di ikuti huruf yang sama berbeda nyata menurut uji lanjut Tukey pada taraf $5 \%$. 
Tabel 4. Memperlihatkan bahwa, perlakuan A berbeda tidak nyata dengan $\mathrm{B}$, tapi berbeda nyatadengn $\mathrm{C}$ dan $\mathrm{D}$, perlakuan $\mathrm{B}$ tidak berbeda nyata dengan C, tapi berbeda nyata $\mathrm{A}$ dan D, perlakuan $\mathrm{C}$ berbeda tidak nyata dengan $\mathrm{D}$, tapi berbeda nyata dengan perlakuan A. Dari perlakuan tersebut dapat disimpulkan bahwa, semakin besar konsentrasi air kelapa yang ditambahkan dalam pembuatan permen air kelapa, maka kandungan kadar gula juga semakin meningkat. Sebaliknya semakin sedikit air kelapa yang digunakan, maka kandungan kadar gula juga semakin sedikit.

Rendahnya kadar gula pada perlakuan A disebabkan karenaair kelapa mengandung sukrosa, hal ini sangat berpengaruh adanya kandungan gula jika dikaitkan dengan gula sukrosa seperti yang terdapat perlakuan D $(50 \%$ air kelapa/bb : $10 \%$ air/bb). Kadar gula permen air kelapa terhadap perbandingan air kelapa dan air berkisar antara $39.0005 \%$ - $44.5914 \%$. Kadar gula tertinggi diperoleh dari perlakuan D $=(50 \%$ air kelapa $/ \mathrm{bb}: 10 \%$ air $/ \mathrm{bb})$ yaitu 44.5914 semakin banyak air kelapa maka semakin tinggi konsentrasi gula reduksi dan semakinrendah air kelapa maka konsentrasi gula semakin rendah seperti yang terdapat pada perlakuan A (20\% air kelapa/bb : $40 \%$ air/bb ) 8.1160 .
Pendidihan larutan sukrosa dalam perbandingan yang berbeda-beda dalam kondisi asam akan terjadi proses hidrolisis yang menghasilkan gula reduksi yang berbeda-beda pula. Dalam proses pendidihan sukrosa ini akan terjadi pemecahan sukrosa menjadi glukosa dan fruktosa akibat pengaruh asam dan panas yang akan meningkatkan kelarutan gula. Hal ini sesuai dengan pendapat (Winarno 1997), bahwa peningkatan gula pereduksi disebabkan selama proses pendidihan larutan sukrosa mengalami inverse atau pemecahan sukrosa manjadi glukosa dan fruktosa akibat pengaruh asam dan panas yang akan meningkatkan kelarutan gula.

\section{Derajat Keasman (pH) Permen}

Derajat keasaman digunakan untuk menyatakan tingkat keasaman basa yang dimiliki oleh zat, larutan atau berbeda. $\mathrm{pH}$ normal berkisar 7 nilai $\mathrm{ph}>$ 7 menunjukan basa dan $\mathrm{pH}<$ menunjukan asam.

Hasil analisis sidik ragam menunjukan bahwa jika $\mathrm{F}$ hitung lebih besar dengan $\mathrm{F}$ tabel $(60.18>4.07)$ maka dilakukan uji lanjut Tukey dengn taraf 5 $\%$, hal ini berarti bahwa perbandingan air kelapa dan air memberikan pengaruh yang berbeda nyata terhadap derajat keasaman $(\mathrm{pH})$ yang di hasilkan.

Tabel 5. Rata-rata Derajat Keasaman (pH) Permen Air Kelapa berdasarkan Perbandingan Air kelapa dan Air

\begin{tabular}{|c|c|}
\hline Perlakuan & Derajat Keasaman $\mathrm{pH}(\%)$ \\
\hline $\mathrm{D}=(20 \%$ air kelapa/bb $: 40 \%$ air/bb $)$ & $2.29 \mathrm{a}$ \\
\hline $\mathrm{C}=(30 \%$ air kelapa/bb $: 30 \%$ air/bb $)$ & $6.59 \mathrm{a}$ \\
\hline $\mathrm{B}=(40 \%$ air kelapa/bb $: 20 \%$ air/bb $)$ & $6.68 \mathrm{c}$ \\
\hline $\mathrm{A}=(50 \%$ air kelapa/bb $: 10 \%$ air/bb $)$ & $6.81 \mathrm{~d}$ \\
\hline
\end{tabular}

Keterangan: Angka-angka yang di ikuti huruf yang sama berbeda nyata menurut uji lanjut Tukey pada taraf 5\%. 
Tabel 5. Memperlihatkan bahwa, perlakuan $\mathrm{D}$ tidak berbeda nyata dengan $\mathrm{C}$, tapi berbeda nyata dengan $\mathrm{B}$ dan $\mathrm{A}$, perlakuan $\mathrm{C}$, berbeda nyata dengan $\mathrm{B}$, tapi tidak berbeda nyata dengan $\mathrm{D}$, perlakuan $\mathrm{B}$, berbeda nyata dengan $\mathrm{A}$, perlakuan A berbeda nyata dengan $\mathrm{D}$ dan C. Dari perlakuan tersebut dapat disimpulkan bahwa, semakin besar konsentrasi air kelapa yang ditambahkan dalam pembuatan permen air kelapa, maka kandungan keasaman permen air kelapa juga semakin meningkat. Sebaliknya semakin sedikit air kelapa yang digunakan, maka kandungan air juga semakin sedikit. Rendahnya kandungan asam yang dihasilakan pada perlakuan A disebabkan karenaair kelapa mengandung sukrosa, pruktosa dan laktosa. hal ini sangat berpengaruh terhadap keasaman yang dihasilkan seperti yang terlihat pada perlakuan A (50\% air kelapa/bb : $10 \%$ air/bb). 6.81 . Hal ini sesuai dengan pendapat Astawan (1991) bahwa pH pruduk minimun dari buah-buahan sebaiknya diatur pada level asam, untuk mencegah perkembangan bakteri atau cendawan maupun khamir yang hidup dalam suasana asam. Di samping itu juga untuk menimbulkan cita rasa yang lebih segar.

Penambahan konsentrasi air yang cukup tinggi dapat membuat $\mathrm{pH}$ menjadi rendah, karena terjadi hidrolisis sukrosa yang mana trjadi penurunan $\mathrm{pH}$ sebab dalam aktivitasnya, sel khamir akan menghasilkan etenol dan mengahsilkan asam-asam organik seperti asam asetat, laktat, malat dan tartarat (Safari, 1995).

\section{KESIMPULAN DAN SARAN}

\section{Kesimpulan}

Dari hasil penelitian terhadap hasil rancangan percobaan dari beberapa perlakuan, maka dapat ditarik kesimpulan bahwa perlakuan terbaik terdapat pada A $(20 \%$ air kelapa/bb : $40 \%$ air/bb) dengan kadar air total 8.1160, dengan hasil uji organoleptik yang di sukai panelis, warna $3,8500 \%$ aroma $3.7000 \%$, rasa 3. 6500, dan tekstur 3.4500. pada pembuatan permen air kelapa dengan penambahan air $10 \%, 20 \%$, 30\%, dan 40\%. Belum menghasilkan permen kadar air dengan standar SNI.

\section{Saran}

Pada pembuatan permen dengan penambahan air 10\%, 20\%, 30\%, dan $40 \%$ belum menghasilkan permen kadar air dengan standar SNI. Sehingga perlu adanya penelitian lanjut dengan menggunakan konsentrasi air lebih tingi.

Pada pembuatan permen air kelapa ini memiliki warna yang kurang menarik. Oleh karena itu, sebaiknya pada penelitian selanjutnya dalam pembuatan permen di tambahkan lagi bahan tambahan pangan berupa pewarna alami sehingga dapat menciptakan warna yang menarik.

\section{DAFTAR PUSTAKA}

Ali S. 1988. Aspek-aspek Fisika Kimia serta Proporsi Bahan-bahan Pembentuk Geldalam pengolahan Permen. Skripsi. FATETA IPB Bogor.

Anonim 2010. Permen Toffee. http;//lordbroken. Wordpress Com/page 11 September 2011.

Badan Standar Nasional Indonesia No3354-1994 SNI kembang Gula. BSNI. Jakarta.

Baramuli, A.N dan A. lay.1997. Pengembangan Industri Kelapa Parut Kering PT. Unnocotin di Sulawesi utara. HLM. 48-56. Prosiding Temu Usaha Perkelapaan Nasional, Manado, 6-8 Januari 1997 . Buku II Balai 
Penelitian Tanaman Kelapa dan Palma Lain, manado.

Buckle KA Ra. Edward GH, Fleet dan M Wooton. 19887 Ilmu Pangan Penerjamah Hari Purnomo dan Adiono. UI Press. Jakarta.

Cholifah. 2012. Potensi Kabupaten 2012.

Kabupaten

Wonosobo

Avalailable. http:/www.

kabupaten wonosobo.

Com/index.php. mudul $=32333123$

3 Openet: 06.02.2012. Anowonsobo. Com

Faridah. Anni dkk, 2008. Pateseri Jillid 3, Dapertemen Pendidikan Nasional Jakarta.

Junk. WR dan Pancoas, H. 1980, Handbookof Sugar. The Avi Publising Company, Ilc westport connecticut.

Lutony, Tony. L. 1993. Tanaman Sumber Pemanis. PT Penebar Swadaya. Jakarta.

Marta, Herlina. 2007, Pengruh Penggunaan jenis gula dan konsenterasi Sari buah terhadap Beberapa Karakteristik Sirup Jeruk Keprok Garut (Citrus noblisiss lour). http Pustaka unpad ac ,id/wpcontent.19 juli 2011 Makassar.

Malik, Iwan 2010. Permen Jelly Yup,http;//iwan.

Wodpress.com/2010/permen jelly/(Januari 2012).

Nuraini H.2007, Mwmilih dan membuat jajanan anak yang sehat dan Halal . Qultum Media, Jkarata.

Suahardinao. L.(1993), Tenaman Kelapa, Penerbit Kanisius, Yogyakarta.

Sholeh. 1978. Penetaran pengusaha Kecil Kembang Gula di daerha
Semarang dan Sekitarnya, semarang : Balai Penelitian Semarang.

Suharto, 1989 Analisa Tepung Hungkue, Mkaroni dan Kembang Gula Balai Industri, Semarang.

Suhardiman. (1999), Kidbloq. Blogskop. Com/2013/04 Air kelapa.

Standar Nasional Indonesia 3542.2 2008 Revisi Kembang Gula Lunak (jelly) Dapertemen Perindustrian.

Soekarno T, S.1985 Penelian Organoleptik Untuk Industri Pangan dan Hasil Pertanian Bhtera Karya Aksara, jkarta.

Sherinton dan Gaman (1994) Pengaruh Pendidikan konsentrasi Sukrosa dengan Sirup.

Suharto, F.G dan S. Laksami (1984). Pigmen pengolahan pangan, depertemen THP IPB, Bogor.

Suekarto T, S. 1985. Penelian Organoleptik Untuk Industri pangan dan Hasil pertanian. Bahtera Karya Aksara. Jakarta.

SNI Standar Nasional Indonesia. 0131440. 2005 Gula Kristal Putih Jakarta: Badan Standarisasi.

Winarno, F.G 1997 Kimia Pangan dan Gizi, PT Gramedia Pustaka Utama jakarta.

Winarno, F.G. 2004. Keamanan Pangan Jillid 1. Bogor : M-Brio Press.

Winarno, F. G. 2002. Ilmu Pangan Dan Gizi. Gramedia Pustaka Utama. Jakarta.

Winarno, F. G. 1983. Enzim Pangan. Gramedia Pustaka Utama. Jakarta.

Winarno, F. G. 1993. Kimia Pangan Dan Gizi. Gramedia Pustaka Utama. Jakarta. 